\title{
DIREITO ADMINISTRATIVO DA EMERGÊNCIA E A COVID-19: A SUBMISSÃO DAS RELAÇÕES JURÍDICAS E OS REFLEXOS DA MEDIDA PROVISÓRIA N. 966/2020 NO QUE TANGE A RESPONSABILIDADEDOS AGENTES PÚBLICOS
}

\author{
EMERGENCY'S ADMINISTRATIVE LAW AND COVID-19: THE SUBMISSION OF \\ LEGAL RELATIONS AND THE REFLECTIONS OF PROVISIONAL MEASURE N. \\ 966/2020 REGARDING THE RESPONSIBILITY OF PUBLIC AGENTS
}

\section{RESUMO}

O presente artigo tem como objetivo analisar os reflexos da Medida Provisória (MP) $n^{\circ}$ 966/2020 que dispõe sobre a responsabilização de agentes públicos por ação e omissão em atos relacionados com a pandemia de Covid-19, caracterizando-se assim, o chamado "direito administrativo da emergência" que, traz à tona transfigurações de todo o sistema afetando as relações jurídicas preexistentes. Primeiramente, a fim de contextualizar a questão, será identificada a responsabilidade civil do agente público, como também do Estado perante o ordenamento jurídico pátrio. Em seguida, investiga-se a necessidade e relevância da referida medida, em contraponto com os mandamentos normativos já existentes, em especial, a Lei de Introdução as Normas do Direito Brasileiro (LINDB) e o Decreto regulamentador de $n^{\circ}$ 9.830/2019. Por fim, será analisado os impactos dos atos de agentes públicos na vigência da MP nº 966/2020 à luz da legislação pátria, bem como pela interpretação acerca dos limites impostos pelo Supremo Tribunal Federal, haja vista a rejeição tácita, em razão do escoamento do prazo legal.

Palavras-chave: Direito Administrativo daEmergência. Pandemia. Responsabilidade civil. Agente Público. Medida Provisória nº 966/2020.

\section{ABSTRACT}

This article aims to analyze the consequences of Provisional Measure (MP) No. 966/2020, which provides for the accountability of public agents for action and omission in acts related to the Covid-19 pandemic, thus characterizing the so-called "administrative law of emergency" which, brings to light transfigurations of the entire system affecting pre-existing legal relationships. First, in order to contextualize the issue, the civil liability of the public agent will be identified, as well as that of the State before the national legal system. Then, the need and relevance of that measure is investigated, in contrast to the already existing normative commandments, in particular, the Law

${ }^{1}$ Pós-Graduada em Compliance, Lei Anticorrupção e Controle da Administração Pública pela Faculdade de Direito de Vitória (FDV). Pós-Graduada em Direito Individual e Processual do Trabalho pela Faculdade de Direito de Vitória (FDV). Advogada e Procuradora da Câmara Municipal de Viana/Es.

${ }^{2}$ Acadêmica em Direito da Faculdade de Direito de Cachoeiro de Itapemirim (FDCI). Estagiária do Ministério Público Estadual. (MPES).

${ }^{3}$ Doutoranda em direito pela Faculdade de Direito de Vitória (FDV). Mestre em Direito pela Faculdade de Direito de Vitória. Bolsista pela FAPES. Advogada. 


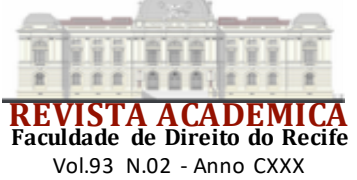

of Introduction to the Rules of Brazilian Law (LINDB) and the Regulatory Decree No.9,830/2019. Finally, the impacts of the acts of public agents under MP no. 966/2020 will be analyzed in the light of Brazilian legislation, as well as the interpretation of the limits imposed by the Supreme Court, given the tacit rejection, due to the flow of the legal term.

Keywords: Emergency Administrative Law. Pandemic. Civil responsability. Public Agent. Provisional Measure N. 966/2020.

\section{INTRODUÇÃO}

Em decorrência do Estado de calamidade pública decretado pela pandemia do novo coronavírus (Covid-19), inúmeras foram as modificações e inserções de novos parâmetros e legislações no ordenamento jurídico brasileiro, com o fim de buscar eficiência de controle e combate.

Nesse contexto, o direito administrativo da emergência traz à tona transfigurações de todo um sistema, ao passo que, a pandemia tem afetado as relações jurídicas preexistentes, o que por sua vez, demandou um ativismo de medidas legislativas e administrativas com o encalço de suspender e, até mesmo, modificar regras vigentes que supostamente não possuíam, por notoriedade, capacid ade de reger este período atípico da sociedade contemporânea. A emergência exigiu providências práticas imediatas, com fundamento na inviabilidade da manutenção da aplicação do direito anterior.

Nesse ínterim, uma das medidas que desencadeou repercussões no âmbito jurídico por tratar de um regime especial de responsabilização de agente público, foi a Medida Provisória (MP) n 966/2020, editad a pelo Presidente da República.

Diante disso, a presente pesquisa se propõe, antes de analisar os principais aspectos da referida medida, a esclarecer as perspectivas tradicionais que baseiam a teoria da responsabilidade civil dos agentes públicos fora do contexto da pandemia e da responsabilidade civil do Estado. Serão também analisadas as regras contidas na MP n n $^{\mathbf{0}} 966 / 2020$, em contraponto com os mandamentos similares já existentes na Lei de Introdução as Normas do Direito Brasileiro (LINDB) e no Decreto ${ }^{\circ}$ 9.830/2019.

Em suma, o presente estudo questiona a repercussão da necessidade e relevância da referida medida provisória em tempos de pandemia, além de avaliar as possíveis implicações desta no âmbito do regime de responsabilidade civil do agente público e do Estado.

Buscar-se-á também compreender quais foram os limites impostos pelo Supremo Tribunal Federal à interpretação da MP nº 966/2020, à luz de recente decisão judicial proferida e eventuais consequências disso, uma vez que a referida medida teve rejeição tácita em função do escoamento do prazo legal, razão pela qual não houve promulgação de lei sobre o tema.

Assim, a situação emergencial impôs certa submissão das relações jurídicas em curso a um Direito Administrativo da Emergência. Considerando a atualidade do tema e a necessidade de sua discussão tanto no meio acadêmico quanto em termos práticos, este estudo se propõe a perquirir a possibilidade de responsabilização de agentes públicos por atos relacionados com a pand emia da COVID-19 à luz da Medida Provisória n 966/2020 e da Lei de Introdução as Normas do Direito Brasileiro (LINDB).

\section{A RESPONSABILIDADE CIVIL DO AGENTE PÚBLICO E DO ESTADO}




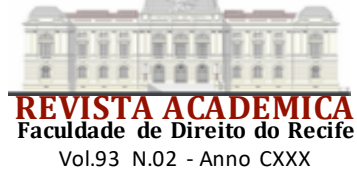

Para apurar o tipo de responsabilidade é necessário distinguir duas situações. A primeira é quando o dano foi causado pelo agente público ao Estado, de forma a gerar três hipóteses de responsabilização cabíveis, a depender da análise de cada caso concreto. E a segunda, é quando o dano causado pelo agente público envolve terceiros, gerando, incialmente a responsabilização do Estadoe, em consequência, a possibilidade de ressarcimento por parte do agente público causador.

Em relação à responsabilização do agente público pelo dano causado ao Estado, tem-se a possibilidade de repercussão em três âmbitos de responsabilidade: o administrativo, o cível e o penal, não caracterizando bis in idem, por se tratar de punições em esferas distintas. Esses tipos de responsabilizações não podem ser confundidos com a responsabilização do Estado, em que o agente público será responsabilizado por dano causado a terceiros, nos moldes do artigo 37 , $\S 6^{\circ}$ da Constituição Federal em ação de regresso.

$\mathrm{Na}$ esfera civil, a responsabilização pode se dar pela decorrência de atos de improbidade e ação de ressarcimento por ilícito civil. Nesse quadro, a responsabilização civil é de cunho patrimonial, de modo que, todo aquele que causa algum tipo de dano a outrem é obrigado a reparálo. Para a configuração do ilícito civil é necessária a caracterização de uma ação ou omissão antijurídica; culpa ou dolo; nexo de causalidade e a ocorrência de um dano. Nesse sentido há a análise se o dano foi causado a um terceiro ou ao Estado, para se distinguir a responsabilidade civil do Estado e do agente público.

Na responsabilização decorrente da esfera administrativa, a Administração Pública atua no âmbito interno, basicamente exercendo o poder disciplinar, de modo que, essa sanciona seus agentes cometedores de infrações disciplinares, por ações ou omissões contrárias à lei, culpa ou dolo e dano, de forma a agir perante todo e qualquer agente público. Em outras palavras, a infração deverá ser apurada pela própria Administração, resguardando os princípios do contraditório e ampla defesa. Os mecanismos de apuração previstos nas leis estatutárias são os sumários e o processo administrativo disciplinar, conhecido pela sigla PAD (DI PIETRO, 2019, p. 1368).

$\mathrm{Na}$ esfera federal, as penalidades administrativas, estão consubstanciadas em um rol taxativo da Lei $\mathrm{n}^{\circ} 8.112$ de $1990^{4}$, sendo elas: advertência, suspensão, demissão, cassação da aposentadoria, cassação da disponibilidade e destituição do cargo em comissão e da função de confiança. De acordo com o princípio da proporcionalidade e razoabilidade, respaldando em um critério de justiça, é necessário levar em consideração a natureza e a gravidade da infração; os danos dela decorrentes para o serviço público; as circunstâncias atenuantes e agravantes, bem como os antecedentes funcionais.

Na responsabilização criminal, o servidor público responderá penalmente pela prática de crime ou contravenção penal. Nesse viés, é necessário que o fato seja típico, ilícito e culpável. O Código Penal, em seu art. 327, preocupou-se em definir o conceito de funcionário público, como aquele que "[...] embora transitoriamente ou sem remuneração, exerce cargo, emprego ou função pública.".

Nesse sentido, independente do âmbito de responsabilização em que o agente público se encontre, esse sempre será responsabilizado subjetivamente, ou seja, é necessário que no comportamento do servidor haja um elemento subjetivo (dolo ou culpa - imprudência, negligência ou imperícia). Faz-se importante a ressalva de que a responsabilidade do agente público não interfere na responsabilidade do Estado. Dessa forma, o ato praticado pelo agente público pode gerar responsabilização em esferas distintas, que poderão ser aplicadas de forma cumulativa, caminhando independente uma da outra, salvo ação penal em caso de absolvição por negativa de autoria ou inexistência do fato (OLIVEIRA, 2018, 421). Dessa forma, se absolvido no penal, o resultado será o mesmo nas demais esferas.

\footnotetext{
${ }^{4}$ Importante salientarque a Lei ${ }^{\circ} 8.112 / 90$ trata sobre as responsabilidades dos servidores federais, mas também contém dispositivos que podem ser aplicados nas demais esferas, o que não afasta a possibilidade de regulamentação das especificidades em âmbito estaduale municipal.
} 


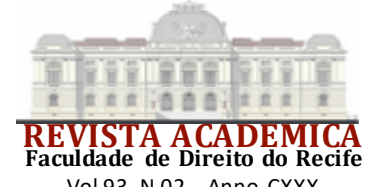

Vol.93 N.02 - Anno CXXX

Sob esse prisma, explicita Carvalho Filho (2020, p. 1024) que o fato gerador da responsabilidade possui variantes de acord o com a natureza jurídica da norma que o contempla. Por isso, os diversos tipos de responsabilidade ou, dito de outra forma, a diversidade de normas que correspondem a diversidade dos tipos de responsabilidades existentes no ordenamento jurídico.

Quanto à responsabilidade do Estado em si, o artigo 37, § $6^{\circ}$, da $\mathrm{CF} / 88$ prevê a responsabilidade civil objetiva das pessoas de direito público, ao mesmo tempo em que amplia a sua incidência para englobar as pessoas jurídicas de direito privado também prestadoras de serviços públicos, por danos causad os a terceiros. Assegurou, ainda, o direito de regresso ao Estadoem face de seus respectivos agentes que responderão de forma subjetiva.

A responsabilidade civil objetiva fica caracterizada quando há a presença de somente três elementos, quais sejam: A conduta estatal, quer lícita, quer ilícita, comissiva ou omissiva; o dano indenizável, não somente econômico, mas jurídico, certo, especial e anormal. E por fim, o nexo de causalidade. Basta, portanto, o liame entre a conduta e o resultado, afastando, assim, o dolo e a culpa, que são elementos vislumbrados pela teoria subjetiva.

Em outras palavras, a responsabilidade do Estado perante terceiros é objetiva, ou seja, independe da presença de dolo ou de culpa, ao passo que a responsabilidade dos agentes públicos é pessoal e subjetiva, de modo que há uma dualidade de regimes de responsabilidade civil convivendo no mesmo artigo (OLIVEIRA, 2018, p. 820).

O Estado será responsável pelos danos causados por seus agentes, nessa qualidade. $\mathrm{O}$ alcance do termo "agentes" é abrangente, compreendendo-o de extrema carga subjetiva, de forma a englobar, toda e qualquer pessoa física que esteja em exercício de uma determinada função pública, incluindo-se nesse rol: os agentes políticos; servidores públicos de regime estatutário, celetistas e temporários, bem como os particulares em colaboração (OLIVEIRA, 2018, p. 820). Além desses, os agentes públicos de fato, ou seja, aqueles que embora estejam em investidura irregular, encontram-se na aparência, quais sejam, os putativos e necessários.

Ocorrend o o evento danoso, há por parte do lesado, o direito a reparação, que poderá ser pela via administrativa ou judicial. Por meio da via administrativa, a qual está condicionada a um consenso em relação aos valores da indenização, a responsabilidade será apurada por meio de processo administrativo, resguardando os princípios da ampla defesa e do contraditório. Admitese, nessa hipótese, o pagamento integral em um único ato ou na forma de trato sucessivo, além das possibilidades de devolução de bens perdidos pela vítima ou a entrega de bens novos.

Por meio da via judicial, o lesado poderá demandar em face do Estado, respaldado pela teoria da responsabilidade objetiva, não podendo reivindicar indenização diretamente do agente público. Ao julgar o Tema 940 de Repercussão Geral, o Supremo Tribunal Federal consolidou esse entendimento, consagrando a tese da dupla garantia prevista no art. $37, \S 6^{\circ}$, da CF/88:

A teor do disposto no art. $37, \S 6^{\circ}$, da Constituição Federal, a ação por danos causados por agente públicodeve ser ajuizada contra o Estado ou a pessoajurídica de direito privado prestadora de serviço público, sendoparte ilegítima para a ação o autor do ato, assegurado o direito de regresso contra o responsável nos casos de dolo ou culpa. (BRASIL, 2019)

Inclusive, em consonância com o entendimento predominante, expõe Oliveira (2018 p. 823) que tampouco se admite denunciação da lide pelo Estado ${ }^{5}$, pois prejudicaria a celeridade processual, além de frustrar o caráter protetivo da vítima previsto no art. $37, \S 6^{\circ}$, da CF/88.

\footnotetext{
${ }^{5}$ Basicamente, a denunciação da lide consiste em uma forma de intervenção de terceiro abarcada pelo direito processual civil, a qual caracteriza -se quando o autor ou réu de uma ação judicialchama um terceiro para o processo.
} 


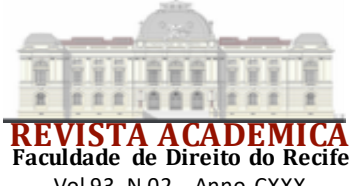

Vol.93 N.02 - Anno CXXX

Nesse caso, o Estado chama para o processo o agente público causador do dano, com a finalid ade de ser ressarcido pelos prejuízos causados através da conduta do servidor. Porém, várias razões justificam a inadmissão da denunciação da lide pelo Estado, como por exemplo a distinção de teorias que abarcariam uma mesma relação processual, sendo o caso da objetiva para o Estado e subjetiva para o agente público, nesse sentido, como essas teorias possuem elementos definidores diferentes o conjunto probatório também deveria ser distinto.

Além disso, para o Estado chamar ao processo o agente, seria necessário demonstrar a culpa ou dolo do funcionário público, o que consequentemente acarretaria ao Estado assumir a sua responsabilização, haja vista que a pessoa jurídica responde pelos atos de seus agentes. (MARINELA, 2019, p. 958)

Nesse contexto, a fim de buscar a compensação das despesas sofridas pelo Estado em decorrência da conduta de seu funcionário, havendo indenização por meio do Ente Estatal pelos atos praticados por seus agentes, se esse houver agido abarcado pelos elementos volitivos culpa ou dolo, a doutrina e a jurisprudência entendem como possível a denominada ação de regresso em face do agente público. Buscar-se-á, assim, o ressarcimento dos prejuízos causados aos cofres públicos. Em síntese, primeiro o Estado paga a indenização ao particular e, somente depois, busca o ressarcimento considerand o o patrimônio do agente público.

Portanto, após a compressão dos principais pontos do sistema de responsabilidade civil dos agentes públicos e do Estado, passa-se agora ao estudo da Medida Provisória nº 966/20, a fim de compreender se as previsões normativas ali contidas afetam ou não, de algum modo, ao referido sistema.

\section{A INFLUÊNCIA DA LEIDE INTRODUÇÃO AS NORMAS DO DIREITOBRASILEIRO E DO DECRETO $\mathrm{N}^{\circ}$ 9.830/2019 NAS DISPOSIÇÕES DA MEDIDA PROVISÓRIA $\mathbf{N}^{\circ}$ 966/2020}

A Medida Provisória, conhecida como MP, é um ato normativo ou regulamentar editado pelo Presidente da República que tem força de lei. Trata-se da ferramenta que permite ao Chefe do Executivo legislar sobre certas matérias que não poderiam aguardar todo o trâmite do processo legislativo. O caput do artigo $62 \mathrm{da} \mathrm{CRFB} / 88$ estabelece que as medidas provisórias só têm cabimento em casos de relevância e urgência.

Assim, a dogmática de exceção demanda arranjos regulatórios apropriados para a emergência que lhes acompanha, quer seja para que haja preponderância do interesse populacional, quer seja para regular as situações jurídicas atinentes aos funcionários públicos, os quais, em um período excepcional, se enquadram no seio de uma representação estatal mais visível.

Nesse contexto, em 13 de maio de 2020 o Presidente da República editou a Medida Provisória $n^{\circ}$ 966/2020, a qual estabelece parâmetros para análise da existência de responsabilização de agentes públicos por ação e omissão em atos relacionados com a pandemia da Covid-19. De acordo com o art. $1^{\circ}$ do seu texto normativo, as condutas dos agentes públicos poderão ser suscetíveis de responsabilização, em âmbito civil e administrativo, somente se praticadas com dolo ou erro grosseiro.

Antes até de adentrar nas suas disposições específicas para fins de compreender a pertinência ou não de tais regras, ressalta-se que, embora surpreendente para muitos, a grande maioria de suas previsões já integrava o nosso ordenamento jurídico, como será demonstrado a seguir.

A Lei de Introdução as Normas do Direito Brasileiro (LINDB), por si só, é uma grande fonte influenciad ora de todos os ramos do ordenamento jurídico pátrio. Suas disposições tratam, em suma, sobre a aplicação das normas jurídicas no tempo e no espaço. Trata-se de uma lei que contém normas gerais, de direito intertemporal, de Direito Internacional Privado, de hermenêutica e de cooperação jurídica internacional. 


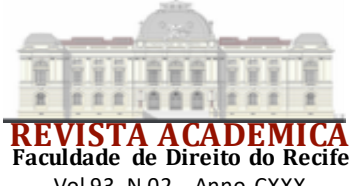

Vol.93 N.02 - Anno CXXX

Nesse sentido, cabe a análise da influência direta da LINDB e do Decreto ${ }^{\circ}$ 9.830/2019, que regulamenta disposições daquela, nas normas recentemente contidas na Medida Provisória $\mathrm{n}^{\circ}$ 966/2020, que surgiu em consequência da decretação do estad o de calamidade pública decorrente da pandemia da covid-196. Nesse sentido, faz-se necessária a análise da real relevância da MP 966/2020, haja vista que as regras contidas nesse sistema se encontravam, em grande parte, já positivadas no ordenamento jurídico brasileiro, como será a seguir demonstrado.

A princípio, a referida medida provisória, surge em um períod o de exceção administrativa, necessitando de atenção na prática das normas por ela impostas, com olhos cautelosos no ambiente de urgência. A norma dispõe sobre as possibilidades de responsabilização, em seu artigo $1^{\circ}$, nos moldes de um regime especial, dos agentes públicos nas esferas civil e administrativas pela prática de condutas omissivas ou comissivas realizadas nos parâmetros dos elementos volitivos dolo ou erro grosseiro, como se vê:

Art. 1 Os agentes públicos somente poderão ser responsabilizados nas esferas civil e administrativa se agirem ou se omitirem com dolo ou erro grosseiro pela prática de atos relacionados, direta ou indiretamente, com as medidas de:

I - Enfrentamento da emergência de saúde pública decorrente da pandemia da covid-19; e

II - Combate aos efeitos econômicos e sociais decorrentes da pandemia da covid19.

Ocorre que, na própria LINDB, já há dispositivos afetos ao direito administrativo, prevendo de modo idêntico, em seu artigo 28, desde 2018, a hipótese de responsabilização do agente público somente para os casos em que configurado dolo ou erro grosseiro. Dessa mesma forma, também o Decreto ${ }^{\circ} 9.830$ de 2019, que regulamenta a Lei de Introdução as Normas do Direito Brasileiro, assim elucida em seu artigo 12: “ $\mathrm{O}$ agente público somente poderá ser responsabilizado por suas decisões ou opiniões técnicas se agir ou se omitir com dolo, direto ou eventual, ou cometer erro grosseiro, no desempenho de suas funções.”.

Porém, apesar da MP 966/2020 abarcar situações já positivadas no ordenamento jurídico pátrio, conforme demostrado, uma distinção dessa medida com a LINDB diz respeito à segurança por meio da qual os agentes públicos teriam na prática de seus atos para o enfrentamento da pandemia, de modo que eventuais erros escusáveis não acarretariam responsabilização. Esses agentes possuem um leque maior de liberdade em relação às possibilidades de atos a serem praticados, à medida que a MP 966/2020 excluía a culpa na sua modalidade genérica para configuração da responsabilização por parte dos agentes públicos, minimizando suas responsabilidades no tratamento da doença e no combate aos seus efeitos econômicos.

Além dessas semelhanças, o artigo $12 \S 1^{\circ}$ do Decreto $n^{\circ} 9.830$ de 2019 , elucida a caracterização de erro grosseiro, reproduzido também no artigo $2^{\circ}$ da medida provisória em análise, como se vê em grau comparativo:

Art. $12 \S 1^{\circ}$ do Decreto $n^{\circ} 9.830 / 2019$ : Considera-se erro grosseiro aquele manifesto, evidente e inescusável praticado com culpa grave, caracterizado por ação ou omissão com elevado grau de negligência, imprudência ou imperícia.

Art. $2^{\circ}$ da MP n 966/2020: Para fins do disposto nesta Medida Provisória, considera-se erro grosseiro o erro manifesto, evidente e inescusável praticado com culpa grave, caracterizado por ação ou omissão com elevado grau de negligência, imprudência ou imperícia.

${ }^{6}$ Em 20 de março de 2020, foi reconhecido o estado de cala midade pública, conforme Decreto Legislativo Federal de n. 06 de 2020. 


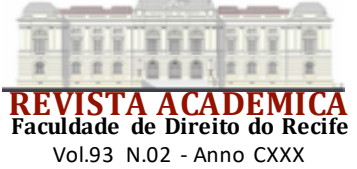

Ainda sobre a configuração do erro grosseiro, o artigo $3^{\circ}$ da MP 966/2020 elencava o que deverá ser analisado para a sua caracterização, sendo flagrante que o referido artigo da medida provisória possui como fonte direta o artigo 22 da LINDB, razão pela qual se propõe uma leitura conjugada dos citados diplomas:

Art. 22 da LINDB: Na interpretação de normas sobre gestão pública, serão considerados os obstáculos e as dificuldades reais do gestor e as exigências das políticas públicas a seu cargo, sem prejuízo dos direitos dos administrados.

Art. $3^{\circ}$ da MP nº 966/2020: Na aferição da ocorrência do erro grosseiro serão considerados:

I - os obstáculos e as dificuldades reais do agente público;

II - a complexidade da matéria e das atribuições exercidas pelo agente público;

III - a circunstância de incompletude de informações na situação de urgência ou emergência;

IV - as circunstâncias práticas que houverem imposto, limitado ou condicionado a ação ou a omissão do agente público; e

$\mathrm{V}$ - o contexto de incerteza acerca das medidas mais adequadas para enfrentamento da pandemia da covid-19 e das suas consequências, inclusive as econômicas.

Nesse panorama, a medida provisória 966/2020, em tese, não é inovad ora, mas novamente aproveita as disposições já existentes tanto na LINDB, quanto no Decreto n 9830/2019, mesclando normas e aplicando no cenário de combate à pandemia da Covid -19 , muito embora 0 artigo $3^{\circ}$, em grau de novidade, aborde situações de extrema importância que acabam por dificultar ainda mais a caracterização do erro grosseiro.

Sobre o tema, conceitua Di Pietro (2019, p. 211) que erro grosseiro é aquele que não admite qualquer tipo de ind agação sobre a sua ocorrência. A figura do erro grosseiro preconiza um conceito jurídico indeterminado, ou seja, sem conteúdo preciso. Ao analisá-lo de acordo com o artigo $2^{\circ}$ da MP 966/2020, ainda assim, surgem ind agações a respeito de quand o o erro é manifesto, inescusável ou evidente. Com isso, depende-se de juízos de valores subjetivos, o que pode gerar diversas interpretações.

Vale destacar que o próprio Tribunal de Contas da União (TCU) já possui entendimento sobre o termo erro grosseiro como o equivalente a culpa grave ${ }^{7}$, tratando-se da conduta do agente público que se afasta daquela que seria esperada do administrador médio, de forma a ser avaliada a depender de cada caso concreto. Nesse viés, erro grosseiro é o evitável por indivíduos com nível de atenção aquém do ordinário. Em outras palavras, erro grosseiro, sob a análise do TCU, em suma, seria aquele que decorreu de um gravame, isto é, que foi praticado com culpa grave (BRASIL, 2020a, p. 1).

Sob esse prisma, a culpa grave ficou caracterizada como aquela perceptível por pessoa com diligência abaixo do normal, daí a ligação com o conceito preceituado acima por Di Pietro (2019, p. 211). Ainda nesses mesmos termos, erro grosseiro seria aquele que poderia ser evitado com elevado grau de atenção, decorrente de grave inobservância do dever de cuidado, pressuposto de toda e qualquer culpa. (GUIMARÃES, 2020, p. 2)

Nesse sentido, é possível a afirmação de que, durante o período de calamidade pública decretado pela pandemia da Covid-19, qualquer agente público, poderia praticar atos julgados

7 Em 2018,o Plenário do TCU proferiu o Acórdão n 2.391, sob a Relatoria do Ministro Benjamin Zymler, que se preocupou em estabelecer diretrizes importantes sobre a responsabilidade dos agentes públicos diante da Lei de Introdução às Normas do Direito Bra sileiro, minuciando a análise do seu artigo 28 da LINDB. 


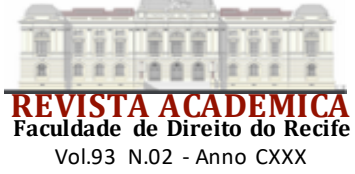

até o momento, tenha sido detectado prejuízos e transtornos decorrentes de sua aplicação. Decorrente disso, a Suprema Corte, por enquanto, limitou-se a analisar, exclusivamente, a MP 966/2020.

Aliás, uma das ações diretas de inconstitucionalidade ajuizadas contra a MP 966/2020 foi a ADI 6428 (cujo objeto é a constitucionalidade da limitação da responsabilidade de agentes públicos), a qual faz indagações específicas em relação ao erro grosseiro compreendido na MP 966/2020. Um dos questionamentos é a vagueza do texto normativo na definição desse termo.

Dentre elas, também há a ADI 6421, ajuizada pelo partido Rede Sustentabilidade na qual sustenta que a Constituição Federal, ao dispor sobre a responsabilização por danos causados por agentes públicos, não faz distinção entre os tipos existentes de culpa (leve, levíssima e grave). Argumenta, ainda, que o conceito de erro grosseiro trazido pela MP 966/2020 é impreciso e vago, criando, assim, obstáculos para a fiscalização e os controles dos atos administrativos.

Feitas essas considerações, importante destacar que a Suprema Corte fixou, liminarmente, tese de que configura o erro grosseiro: "o ato administrativo que ensejar violação ao direito à vida, à saúde, ao meio ambiente equilibrado ou impactos adversos à economia, por inobservância de normas e critérios científicos e técnicos ou dos princípios constitucionais da precaução e da prevenção." (BRASIL, 2020b, p.21).

Uma das alegações era a de que a MP 966/2020 deixa carente de proteção direitos da personalidade individuais indisponíveis, tais como a saúde e a vida da população brasileira. No que tange à proteção da saúde e da vida, especificamente, a jurisprudência do STF adota como base os parâmetros de que as decisões governamentais devem respeitar padrões e evidências científicas relacionadas com essa questão. Outro parâmetro é o de que, situações como essas se sujeitam aos princípios da prevenção e precaução. (CAVALCANTE, 2020, p. 7-8)

Nesse viés, a Suprema Corte deferiu parcialmente a medida cautelar para conferir interpretação do artigo $2^{\circ}$ da norma (que define o conceito de erro grosseiro), conforme à Constituição, uma vez que, para caracterizar o erro grosseiro há a necessidade da avaliação de "standards", normas e critérios científicos e técnicos, além dos princípios constitucionais da precaução e prevenção, vez que, a Administração Pública deve se pautar pela autocontenção em casos de dúvidas quanto à aplicação dos efeitos de uma MP.

Para conferir interpretação do artigo $1^{\circ}$ da MP 966/2020 conforme o texto constitucional, com a finalidade de explicar que para os fins desse dispositivo, a autoridade à qual compete a decisão deve exigir opinião técnica expressamente de normas e critérios específicos relacionados à matéria. Ademais, da mesma forma como a análise do artigo $2^{\circ}$, a necessidade da observância dos princípios da precaução e da prevenção. (BRASIL, 2020b, p. 19).

Nesse sentido, o Ministro Barroso, relator das ações, concluiu que não há inconstitucionalidades na MP 966/2020, porém, a definição de erro grosseiro deve estar em consonância com a Constituição Federal de 1988. Em suma, qualquer que seja o dispositivo legal, deve-se estar em consonância e harmonia com a com a Constituição, ou seja, embora o Estado tenha responsabilidade objetiva nos moldes da teoria do risco administrativo, há que se verificar a responsabilidade subjetiva do agente público seja por dolo ou culpa. Sendo a responsabilidade civil dos agentes públicos disciplinada pela Magna Carta, há que se considerar também a matéria subjetiva que abrange a questão, de forma que o artigo 37, parágrafo $6^{\mathrm{a}}$, aponta que: "as pessoas jurídicas de direito público e as de direito privado prestadoras de serviços públicos responderão pelos danos que seus agentes, nessa qualidade, causarem a terceiros, assegurado o direito de regresso contra o responsável nos casos de dolo ou culpa".

Em outras palavras, pela leitura do referido dispositivo, a responsabilização do ente público é objetiva e seus agentes respondem de forma subjetiva por meio da ação de regresso. Nesse aspecto, o nexo causal é relevante na discussão, haja vista não se tratar de responsabilidade objetiva do agente público, assim, argumentos em torno do princípio da precaução pode romper o 


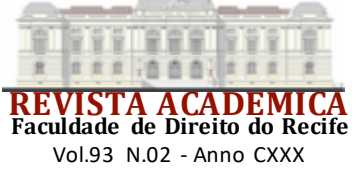

nexo causal pela excepcionalidade da pandemia. Do contrário, seria questão que paira a teoria do risco integral.

Isto posto, de acordo com Di Pietro (2019, p. 813), a responsabilidade extracontratual do Estado corresponde à "[...] obrigação de reparar danos causados a terceiros em decorrência de comportamentos comissivos ou omissivos, materiais ou jurídicos, lícitos ou ilícitos, imputáveis aos agentes públicos. " Na mesma linha de entendimento, Sergio Cavalieri (2014, p. 290-291) ressalta a responsabilidade objetiva do poder público "[...] ao dano decorrente da sua atividade administrativa, isto é, aos casos em que houver relação de causa e efeito entre a atuação do agente público e o dano." (CAVALIEIRI FILHO, 2014, pp. 290-291).

Diante disso, para que seja configurad o o dever de indenizar pelo Estado, é imprescindível a condicionante entre o agente público e sua própria atuação administrativa. No que tange circunstâncias excepcionais de caso fortuito e força maior, o art. 393 do Código Civil pode ser aplicado nos casos de responsabilidade extracontratual, não se caracterizando a responsabilidade do agente em decorrência da ausência do nexo de causalid ade (CAVALIERIFILHO, 2014, p. 8689). Logo, eventos imprevisíveis, como no caso da pandemia ocasionada pela COVID-19, são inevitáveis, ou seja, excludente de responsabilidade.

Tampouco deve-se levar em consideração o ponto controverso relacionado ao chamado "erro grosseiro", uma vez que a própria doutrina e a Suprema Corte entendem que deve ser interpretad o como o erro crasso, isto é, uma culpa grave. Inclusive, o Decreto ${ }^{\circ}$ 9.830/2019 corrobora com tal preceito ao estabelecer que "considera-se erro grosseiro aquele manifesto, evidente e inescusável praticado com culpa grave, caracterizado por ação ou omissão com elevado grau de negligência, imprudência ou imperícia".

A Medida Provisória n. 966/2020, portanto, em nada inovou em termos jurídicos, tendo em vista a Constituição Federal, bem como a possibilidade de aplicação do art. 28 da LINDB para regular a responsabilização de agentes públicos por meio da análise subjetiva e regressiva, mediante a comprovação dos elementos de dolo e culpa. Mesmo porque, diante da rejeição tácita, a prevalência dos efeitos decorrentes deve ser analisada com base nos critérios e legislações vigentes

\section{CONCLUSÃO}

Durante o período de calamidade pública, decretado em decorrência da pandemia da Covid-19 no Brasil, inúmeras foram as atitudes de autoridades públicas tomadas com o objetivo de preservar a vida, a saúde, a integridade e a dignidade da pessoa humana. A MP nº 966/2020, sensível a esse ambiente caótico promovido pela pandemia, trouxe um regime especial de responsabilização de agentes públicos.

Sendo assim, concluiu-se que para os atos administrativos praticados fora do contexto da pandemia do novo coronavírus (Covid-19), os agentes públicos respondem civil e administrativamente, nos termos do art. $37, \S 6^{\circ}$, da CF, dos arts. 20 a 30 da LINDB e também do Decreto n. ${ }^{\circ}$ 9.830/2019. Já para os atos praticados dentro do contexto da pandemia, a responsabilidade civil e administrativa do servidor Público também será regida pela Medida Provisória no 966/2020.

Apontou-se que, embora a referida medida provisória tenha trazido algumas novidades, como a maior segurança jurídica dada aos agentes públicos nesse período de exceção administrativa e a previsão expressa de que os agentes públicos somente poderiam ser responsabilizados nas esferas civil e administrativa, ficou claro que as regras ali contidas não ensejaram uma situação normativa inovadora para o Direito Brasileiro. Isso porque, a maioria dos regramentos nela contidos, já se encontravam positivados em outros conjuntos de normas e diretrizes de um contexto do sistema jurídico. 


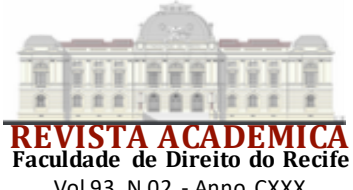

Vol.93 N.02 - Anno CXXX

Ademais, em qualquer caso, seja dentro, seja fora do contexto da pandemia, a responsabilidade civil do Estado por danos causados a terceiros é objetiva, vedado ao terceiro reivindicar indenização diretamente contra o agente público, em razão da teoria da dupla garantia consagrada pelo STF.

Por fim, demonstrou-se que a Suprema Corte brasileira impôs, recentemente, limites à interpretação da MP n ${ }^{\circ}$ 966/2020, em especial, quanto à definição de erro grosseiro na qual deve estar em consonância com a Constituição Federal de 1988, mas frisou que não há inconstitucionalidades, por ora, em tal medida provisória.

$\mathrm{O}$ direito administrativo emergencial continuad amente apresenta ferramentas importantes para os momentos de crise, de modo a conceder medidas excepcionais que visem atender ao interesse público, das mais repercutidas às mais simples, pois como bem dizia Hipócrates, considerado o pai da medicina, "para os males extremos, só são eficazes os remédios intensos." Portanto, tendo em vista o caráter não inovador da MP no 966/2020, os atos praticados pelos agentes públicos na vigência da referida medida devem ser analisados nos preceitos que regem a normalidade, tendo em vista a responsabilidade subjetiva do agente e a excepcionalidade da pandemia ocasionada pela COVID-19.

\section{REFERÊNCIAS}

BRASIL. [Constituição (1989)]. Constituição da República Federativa do Brasil. Disponível em: http://www.planalto.gov.br/ccivil_03/Constituicao/Constituicao.htm. Acesso em: 22 ago. 2020 .

\section{BRASIL. Casa Civil. Decreto $\mathbf{n}^{\circ} \mathbf{9 . 8 3 0}$, de 10 de junho de 2019.}

Regulamenta o disposto nos art. 20 ao art. 30 do Decreto-Lei no 4.657, de 4 de setembro de 1942, que institui a Lei de Introdução às normas do Direito brasileiro. Disponível em:

http://www.planalto.gov.br/ccivil_03/_ato2019-2022/2019/decreto/D9830.htm. Acesso em: 08 jul. 2020.

BRASIL. Casa Civil. Decreto-Lei n ${ }^{\circ} 2848$, de 7 de dezembro de 1940. Código Penal. Brasília: Planalto, 1940. Disponível em: http://www.planalto.gov.br/ccivil_03/decreto-

lei/del2848compilad o.htm. Acesso em: 23 jul. 2020.

BRASIL. Casa Civil. Decreto-Lei ${ }^{\circ}$ 4657, de 4 de setembro de 1942. Lei de Introdução às normas do Direito Brasileiro. Planalto, Brasília, DF, 4 set. 1942. Disponível em: http://www.planalto.gov.br/ccivil_03/decreto-lei/del4657compilado.htm. Acesso em: 08 jul. 2020.

BRASIL. Casa Civil. Lei ${ }^{\circ}$ 8.112, de 11 de dezembro de 1990. Dispõe sobre o regime jurídico dos servidores públicos civis da União, das autarquias e das fundações públicas federais.

Disponível em: http://www.planalto.gov.br/ccivil_03/leis/18112cons.htm. Acesso em: 22 jul. 2020.

BRASIL. Medida provisória $\mathbf{n}^{\circ}$ 966, de 13 de maio de 2020. Dispõe sobre a responsabilização de agentes públicos por ação e omissão em atos relacionados com a pandemia da covid-19. Disponível em: http://www.planalto.gov.br/ccivil_03/_Ato2019-2022/2020/Mpv/mpv966.htm. Acesso em: 08 jul. 2020.

BRASIL. Superior Tribunal Federal. Voto do relator em Ação Direta de

Inconstitucionalidade n. 6421, 6422, 6424, 6425, 6427, 6428 e 6431 MC. Relator: Ministro 
